\title{
Influence of time, toothpaste and saliva in the retention of Streptococcus mutans and Streptococcus sanguinis on different toothbrushes
}

\author{
Julia Caroline SCHMIDT ${ }^{1^{*}}$, Miriam BUX ${ }^{2^{\star}}$, Elisabeth FILIPUZZI-JENNY², Eva Maria KULIK², Tuomas WALTIMO ${ }^{2}$, Roland \\ WEIGER ${ }^{1}$, Clemens WALTER ${ }^{1}$
}

\footnotetext{
1- Department of Periodontology, Endodontology and Cariology, School of Dental Medicine, University of Basel, Basel, Switzerland.

2- Clinic of Preventive Dentistry and Oral Microbiology, School of Dental Medicine, University of Basel, Basel, Switzerland.

* both authors contributed equally to this work.
}

Corresponding address: Clemens Walter - Department of Periodontology, Endodontology and Cariology, School of Dental Medicine - University of Basel Hebelstrasse 3 - 4056 Basel - Switzerland - Phone: +41612672628 - Fax: +41612672659 - e-mail: clemens.walter@unibas.ch

Submitted: January 8, 2013 - Modification: February 6, 2014 - Accepted: March 3, 2014

\section{ABSTRACT}

\begin{abstract}
$\mathrm{O}$ bjectives: The intraoral transmission of cariogenic and periodontopathogenic species seems to be facilitated by contaminated toothbrushes and other oral hygiene devices. The aim of this investigation was to analyze the in vitro retention and survival rate of Streptococcus mutans and Streptococcus sanguinis on different toothbrushes. The impacts of human saliva and antimicrobial toothpaste on these parameters were further evaluated. Material and Methods: Part I: Four toothbrushes (Colgate $360^{\circ}$, Curaprox CS5460 ultra soft, Elmex InterX, Trisa Flexible Head3) were contaminated by S. mutans DSM 20523 or S. sanguinis DSM 20068 suspensions for three minutes. Bacteria were removed from the toothbrushes after either three minutes $\left(T_{0}\right)$ or 24 hours $\left(T_{24}\right)$ of dry storage and grown on Columbia blood agar plates for the quantification of colony-forming units (CFUs). Part II: The effects of saliva from a caries-active or a caries-inactive person and of toothpaste containing $0.12 \%$ chlorhexidine digluconate were also tested. Results: Part I: After three minutes of dry storage, approximately one percent of the bacteria were still detectable on the toothbrushes. After 24 hours, S. sanguinis exhibited a more pronounced decrease in viable cell numbers compared with $S$. mutans but the differences were not significant (Kruskal-Wallis test, $\mathrm{p}>0.05$ ). Part II: The addition of human saliva from a caries-active or caries-inactive person slightly increased the retention of both streptococcal species at $T_{0}$. The use of toothpaste had no influence on the amount of viable streptococci at $T_{0}$, but it reduced the microbial load after 24 hours of storage. There were only slight nonsignificant differences $(p>0.05)$ between the four toothbrushes. Conclusions: In vitro bacterial retention and survival of $S$. sanguinis and $S$. mutans on different toothbrushes occurred. Within the limitations of this study, the use of human saliva or an antimicrobial toothpaste did not lead to significant differences in the microbial load on toothbrushes.
\end{abstract}

Keywords: Toothbrushing. Bacterial adhesion. Streptococcus mutans. Streptococcus sanguinis. Saliva.

\section{INTRODUCTION}

Both periodontitis and dental caries are infectious diseases caused by microorganisms in a pathogenic biofilm. A biofilm is a complex bacterial structure on a solid wet surface that protects microorganisms from the host's immune defense and from antimicrobial agents ${ }^{11}$.

Adequate, self-performed oral hygiene is therefore an integral part of the prevention and treatment of periodontitis and dental caries ${ }^{3}$. Without proper supragingival plaque control, the initiation and progression of oral infectious diseases may occur ${ }^{24}$. The relationship between the amount of plaque accumulation and its pathogenic effect is described by the unspecific plaque hypothesis ${ }^{27}$.

In contrast, the specific plaque hypothesis refers to specific pathogens in the etiology of 
periodontal diseases ${ }^{12}$. This view is supported by the finding that certain bacterial species are more virulent than others ${ }^{11,12}$. The oral cavity naturally harbors a large variety of different bacteria 28 . Streptococcus sanguinis is among the pioneer bacteria in oral biofilm formation preceding the attachment of subsequent colonizers and therefore of great importance in the development of periodontal diseases ${ }^{11}$. Streptococcus mutans is not considered to be a characteristic periodontal pathogen but the major causative microorganism associated with dental caries initiation ${ }^{13}$. However, a dramatic increase of $S$. mutans may occur after non-surgical periodontal therapy, possibly leading to an increased cariogenic activity ${ }^{6}$. The treatment of periodontitis and dental caries should prevent bacterial recolonization due to intraoral transmission of pathogenic bacteria ${ }^{19}$. Transmission of cariogenic and periodontopathogenic species was demonstrated for contaminated toothbrushes and other oral hygiene devices ${ }^{7,14}$. A large variety of different toothbrush designs exist that may facilitate the retention, survival and intraoral transmission of bacteria ${ }^{11}$. To prevent periodontal and cariogenic infection and avoid reinfection, an adequate disinfection of oral hygiene devices such as toothbrushes is considered to be clinically relevant ${ }^{19}$.

The first aim of the present study was to evaluate the adhesion and survival rate of $S$. sanguinis and S. mutans on four different toothbrushes (Part I). The second aim was to investigate the influence of saliva and of an antimicrobial toothpaste on bacterial retention (Part II).

\section{MATERIAL AND METHODS}

\section{Toothbrushes}

Four toothbrushes were tested in this study: Colgate $360^{\circ}$ (Colgate-Palmolive AG, Thalwil, Switzerland), Curaprox CS5460 ultra soft (Curaden AG, Kriens, Switzerland), Elmex InterX (GABA AG,
Therwil, Switzerland), and Trisa Flexible Head3 (Trisa AG, Triengen, Switzerland). The relevant characteristics of the toothbrushes are provided in Figure 1.

\section{Part I}

\section{Bacterial strains and growth conditions}

S. sanguinis DSM 20068 and S. mutans DSM 20523 were obtained from Deutsche Sammlung von Mikroorganismen und Zellkulturen (Braunschweig, Germany) and preserved in $15 \%$ skim milk solution at $-20^{\circ} \mathrm{C}$. For the experiments, $10-\mu$ inoculums of each of the streptococci were suspended in 5 $\mathrm{ml}$ of Schaedler broth (BBL, Becton Dickinson, Basel, Switzerland) and grown aerobically at $37^{\circ} \mathrm{C}$ for either five (S. mutans) or eight ( $S$. sanguinis) hours ${ }^{22}$. Then, $900 \mu \mathrm{l}$ of these bacterial suspensions was transferred to $45 \mathrm{ml}$ of fresh Schaedler broth and aerobically incubated at $37^{\circ} \mathrm{C}$ for 16 (S. mutans) or 20 (S. sanguinis) hours. To determine consistent bacterial counts (CFU/ml) of the bacterial suspensions used to contaminate the toothbrushes, cultures were ultrasonicated for $30 \mathrm{~s}$ with a maximum power of $130 \mathrm{~W}$ (Sonics Vibra Cell VCX130, Huber, Meyrin/Satigny, Switzerland), and appropriate dilutions $\left(10^{-5}, 10^{-6}\right)$ were plated onto Columbia blood agar plates (BBL; Becton Dickinson, Basel, Switzerland) supplemented with $50 \mathrm{ml} / \mathrm{l}$ of human blood, $0.5 \mathrm{mg} / \mathrm{l}$ of menadione and $5 \mathrm{mg} / \mathrm{l}$ of hemin at $37^{\circ} \mathrm{C}$ prior to each experiment ${ }^{2,5,22}$. The plates were incubated anaerobically using atmosphere generation system packs (AnaeroGen ${ }^{\mathrm{TM}}$ Compact, Oxoid, Pratteln, Switzerland) at $37^{\circ} \mathrm{C}$ for one day, and the colonies were then counted.

\section{Retention of streptococci on toothbrushes}

For the retention experiments, two toothbrushes of each brand were aseptically removed from the original wrappings. Each new toothbrush was used once. First, the toothbrush heads were placed in 15 $\mathrm{ml}$ of bacterial suspensions of approximately $5 \times 10^{8}$ $\mathrm{CFU} / \mathrm{ml}$ and left in place for three minutes, such

\begin{tabular}{|c|c|c|c|c|c|}
\hline Model & $\begin{array}{c}\text { Number of } \\
\text { bristles }\end{array}$ & $\begin{array}{c}\text { Dimension of } \\
\text { head }(\mathbf{m m})\end{array}$ & Hardness & $\begin{array}{c}\text { Length of } \\
\text { bristles }(\mathbf{m m})\end{array}$ & $\begin{array}{c}\text { Additional } \\
\text { characteristics }\end{array}$ \\
\hline Colgate $360^{\circ}$ & 1323 & $26 \times 11$ & medium* & $9-12$ & $\begin{array}{c}\text { soft rubber polishing } \\
\text { cups, tongue and cheek } \\
\text { cleaner }\end{array}$ \\
\hline Curaprox CS5460 & $5460^{*}$ & $22 \times 11$ & medium $^{*}$ & 9 & - \\
\hline Elmex nterX & $648-702^{*}$ & $21 \times 9$ & soft $^{*}$ & $10-12$ & $\begin{array}{c}\text { some bristles at a } 60^{\circ} \\
\text { angle to the rest of } \\
\text { bristles }\end{array}$ \\
\hline $\begin{array}{c}\text { Trisa Flexible } \\
\text { Head }\end{array}$ & 1916 & $26 \times 9$ & medium* & $10-12$ & flexible head \\
\hline
\end{tabular}

*as described by the respective manufacturer

Figure 1- Characteristics of the toothbrushes used in the study 
that the head of the toothbrush and approximately $1 \mathrm{~cm}$ of the handle were exposed to the bacterial culture. The time of three minutes was chosen due to the average time usually spent for an oral hygiene session ${ }^{5,25}$. The toothbrushes were then dipped three times in $15 \mathrm{ml}$ of $0.9 \% \mathrm{NaCl}$ and stored with the bristles facing up in a dry environment at room temperature for either three minutes $\left(T_{0}\right)$ or 24 hours $\left(T_{24}\right)$. For microbial analysis, the head of each toothbrush was clipped off, placed in $15 \mathrm{ml}$ of $0.9 \% \mathrm{NaCl}$, vortexed for one minute, ultrasonicated for one minute with a maximum power of $100 \mathrm{~W}$ and again vortexed for one minute. Appropriate dilutions $\left(10^{-0}, 10^{-1}, 10^{-2}, 10^{-3}, 10^{-4}\right)$ were then plated onto Columbia blood agar plates. The plates were incubated anaerobically at $37^{\circ} \mathrm{C}$ for one day, and the colonies were counted.

\section{Part II}

Influence of saliva on the retention of streptococci on toothbrushes

The saliva of two subjects with different caries activity was used in this study. Both subjects were informed regarding the purposes of the study, and informed consent was obtained. The study was approved by the Research Ethics Committee of the University of Basel, Switzerland (EK: 295/08).

Subject 1 (caries-active, CA) was a 25-year-old male student. He had 24 teeth with insufficiently restored carious lesions [decayed, missing and filled teeth $(\mathrm{DMFT})=16]$. Subject 2 (caries-inactive, CI) was a 30-year-old female dental student. She had 28 teeth with no carious lesions (DMFT =1; one filling due to aesthetic reasons). Whole saliva from both volunteers was collected by paraffin stimulation over a three-week period. Saliva was collected in the morning, and the volunteers were advised not to drink or eat overnight. Approximately 35-50 ml of saliva was collected per day in sterile, ice-chilled tubes and stored at $-20^{\circ} \mathrm{C}$. After collecting a total of $350-400 \mathrm{ml}$ of saliva, the samples from each volunteer were gently thawed in cold water, pooled and filtered through a 70- $\mu \mathrm{m}$ filter (Cell Strainer, Becton Dickinson, Basel, Switzerland) into sterile, ice-chilled tubes. The saliva was ultrasonicated for $30 \mathrm{~s}$ with a maximum power of $100 \mathrm{~W}$ and then centrifuged at $21,800 \times \mathrm{g}$ for one hour at $4^{\circ} \mathrm{C}$. The supernatant was filtered through 0.45 - and 0.22 $\mathrm{mm}$ filters (Millex-HV and Millex-GV, respectively; Millipore AG, Zug, Switzerland) and frozen at $-20^{\circ} \mathrm{C}$ in $15-\mathrm{ml}$ aliquots. Before use, the saliva was gently thawed by placing the tubes in cold water, and the $\mathrm{pH}$ value was adjusted to 7 with phosphate buffer $\left(1.5 \mathrm{ml}\right.$ of $491 \mathrm{mM} \mathrm{Na} \mathrm{HPO}_{4}$ and $1.5 \mathrm{ml}$ of $275.6 \mathrm{mM} \mathrm{KH}_{2} \mathrm{PO}_{4}$ per $15 \mathrm{ml}$ of saliva) in order to standardize this parameter. For experiments using bacteria suspended in human saliva, $15 \mathrm{ml}$ of the respective bacterial cultures were centrifuged at
$6,200 \times \mathrm{g}$ for 5 minutes. The bacterial pellets were then washed once with $0.9 \% \mathrm{NaCl}$, harvested again by centrifugation and suspended in $15 \mathrm{ml}$ of buffered saliva ${ }^{25}$. To determine the correct bacterial counts, appropriate dilutions $\left(10^{-0}, 10^{-1}, 10^{-2}, 10^{-3}\right.$, $10^{-4}$ ) were plated onto Columbia blood agar plates. The plates were incubated anaerobically at $37^{\circ} \mathrm{C}$ for one day, and the colonies were counted.

The experimental setup of the retention experiments was identical to that described in Part I, except that the bacteria were suspended in human saliva. The time of dry storage after toothbrush contamination amounted three minutes $\left(T_{0}\right)$.

\section{Influence of toothpaste on the retention of streptococci on toothbrushes}

To examine the influence of antibacterial toothpaste on the retention of streptococci on toothbrushes, the experiments were repeated using a toothpaste containing $0.12 \%$ chlorhexidine digluconate (Curasept ADS 712, Curaden AG, Kriens, Switzerland) at $\mathrm{T}_{0}$ (without saliva, CA, $\mathrm{CI}$ ) and $T_{24}$ (without saliva). The unaltered overthe-counter toothpaste was provided by the manufacturer.

To mimic normal use, $0.5 \mathrm{~g}$ of the toothpaste was applied by repeatedly brushing the agent into the respective toothbrush for $10 \mathrm{~s}$. The toothbrush head was then placed in $10 \mathrm{ml}$ of sterile $0.9 \% \mathrm{NaCl}$ and vortexed for one minute to cause foaming of the toothpaste. Afterward, the retention test with either S. sanguinis or S. mutans was performed as described above.

\section{Analysis}

Two separate experiments were performed for each set of parameters. The retention of the bacteria on each toothbrush was assessed by assessing the difference in bacterial growth (i.e., the $\log _{10}$ number of bacteria CFUs) before and after retention to the toothbrush. A descriptive analysis was also performed. The reductions are shown as the mean- $\log _{10}$ factors and standard deviations, and " $\geq$ " denotes reductions greater than the respective detection limit. A statistical analysis was performed using SPSS ${ }^{\circledR}$ software (SPSS ${ }^{\circledR}$ Statistics 20.0.0; SPSS Inc., Chicago, IL, USA). The nonparametric Kruskal-Wallis test was used to assess the differences between the tested variables. A result was considered to be statistically significant if $p<0.05$.

\section{RESULTS}

\section{Part I}

Retention of streptococci on toothbrushes

The bacterial counts (CFU/ml) used to artificially contaminate the toothbrushes were between 
Table 1- Influence of time, toothpaste and saliva on the reduction of streptococcal retention on four different toothbrushes. Either no saliva or saliva collected from a caries-inactive $(\mathrm{Cl})$ or a caries-active $(\mathrm{CA})$ volunteer was used, and the artificially contaminated toothbrushes were analyzed after either three minutes $\left(T_{0}\right)$ or 24 hours $\left(T_{24}\right)$. The reductions in bacterial counts are shown as the mean-log10 factors and standard deviations. Two independent experiments $(n=2)$ were performed for each set of parameters. A higher number indicates a greater bacterial reduction, and " $\geq$ " denotes reductions to levels below the respective detection limits

\begin{tabular}{|c|c|c|c|c|c|c|c|c|}
\hline \multirow{3}{*}{$\begin{array}{l}\text { Toothbrush and } \\
\text { bacteria }\end{array}$} & \multicolumn{4}{|c|}{ Without toothpaste } & \multicolumn{4}{|c|}{ With toothpaste } \\
\hline & \multicolumn{2}{|c|}{ no saliva } & \multirow{2}{*}{$\begin{array}{l}\mathrm{Cl} \\
\mathrm{T}_{0}\end{array}$} & \multirow{2}{*}{$\begin{array}{l}\mathrm{CA} \\
\mathrm{T}_{0}\end{array}$} & \multicolumn{2}{|c|}{ no saliva } & \multirow{2}{*}{$\begin{array}{l}\mathrm{Cl} \\
\mathrm{T}_{0}\end{array}$} & \multirow{2}{*}{$\begin{array}{l}\mathrm{CA} \\
\mathrm{T}_{0}\end{array}$} \\
\hline & $T_{0}$ & $T_{24}$ & & & $T_{0}$ & $T_{24}$ & & \\
\hline \multicolumn{9}{|l|}{ Colgate $360^{\circ}$} \\
\hline S. sanguinis & $2.15 \pm 0.10$ & $5.84 \pm 0.32$ & $2.04 \pm 0.13$ & $1.96 \pm 0.05$ & $2.15 \pm 0.05$ & $\geq 6.35 \pm 0.13$ & $1.91 \pm 0.08$ & $1.79 \pm 0.17$ \\
\hline S. mutans & $2.16 \pm 0.19$ & $2.97 \pm 0.09$ & $1.76 \pm 0.02$ & $1.78 \pm 0.19$ & $2.27 \pm 0.09$ & $3.5 \pm 0.15$ & $1.70 \pm 0.04$ & $1.94 \pm 0.05$ \\
\hline \multicolumn{9}{|l|}{ Curaprox CS5460 } \\
\hline S. sanguinis & $2.64 \pm 0.01$ & $\geq 6.76 \pm 0.04$ & $2.10 \pm 0.25$ & $2.27 \pm 0.07$ & $2.35 \pm 0.09$ & $\geq 6.25 \pm 0.21$ & $1.95 \pm 0.19$ & $2.04 \pm 0.01$ \\
\hline S. mutans & $2.40 \pm 0.16$ & $3.51 \pm 0.16$ & $2.01 \pm 0.02$ & $2.37 \pm 0.05$ & $2.13 \pm 0.05$ & $5.27 \pm 0.23$ & $1.48 \pm 0.26$ & $1.58 \pm 0.05$ \\
\hline \multicolumn{9}{|l|}{ Elmex interX } \\
\hline S. sanguinis & $2.58 \pm 0.18$ & $\geq 6.59 \pm 0.04$ & $2.23 \pm 0.25$ & $2.11 \pm 0.18$ & $2.36 \pm 0.02$ & $\geq 6.25 \pm 0.01$ & $1.95 \pm 0.22$ & $2.07 \pm 0.12$ \\
\hline S. mutans & $2.12 \pm 0.02$ & $4.04 \pm 0.42$ & $1.93 \pm 0.02$ & $1.86 \pm 0.12$ & $2.53 \pm 0.21$ & $5.48 \pm 0.27$ & $1.96 \pm 0.19$ & $1.96 \pm 0.29$ \\
\hline \multicolumn{9}{|l|}{$\begin{array}{c}\text { Trisa Flexible } \\
\text { Head }\end{array}$} \\
\hline S. sanguinis & $2.47 \pm 0.03$ & $\geq 6.64 \pm 0.01$ & $1.86 \pm 0.17$ & $1.96 \pm 0.13$ & $2.11 \pm 0.06$ & $\geq 6.42 \pm 0.01$ & $1.90 \pm 0.20$ & $2.05 \pm 0.13$ \\
\hline S. mutans & $1.96 \pm 0.04$ & $4.24 \pm 0.14$ & $1.60 \pm 0.11$ & $1.69 \pm 0.17$ & $2.35 \pm 0.13$ & $5.38 \pm 0.07$ & $1.54 \pm 0.19$ & $1.78 \pm 0.17$ \\
\hline
\end{tabular}

$9.8 \times 10^{7}$ and $7.6 \times 10^{8}$ for $S$. mutans and between $1.1 \times 10^{8}$ and $7.5 \times 10^{8}$ for $S$. sanguinis. Of these bacteria, approximately one percent, corresponding to a mean $\log _{10}$ reduction of approximately 2 , was still retained on the toothbrushes after rinsing and three minutes of storage $\left(\mathrm{T}_{0}\right)$ at room temperature (Table 1).

No significant differences in the retention of S. mutans and $S$. sanguinis between the four toothbrushes could be detected. After 24 hours of storage $\left(T_{24}\right)$, a decrease in bacterial retention on the toothbrush heads, compared with the retention at three minutes $\left(T_{0}\right)$, was found for all toothbrushes and both bacteria. For $S$. sanguinis, the reductions in viable cell numbers after one day $\left(T_{24}\right)$ on all toothbrushes were more pronounced compared with S. mutans. The decrease in S. sanguinis bacterial counts was higher than 6 log factors and thereby below the detection limit, except for the Colgate $360^{\circ}$ toothbrush. The differences were not statistically significant $(p>0.05)$.

\section{Part II}

Influence of saliva on the retention of streptococci on toothbrushes

The retention of the two streptococcal species was tested in the presence of saliva isolated from the person with or without caries activity (Table 1 ).

When the two streptococcal species were compared with respect to the presence or absence of either saliva, slightly more bacterial cells remained attached to the toothbrushes at $T_{0}$ when saliva was added. There was no particular preference regarding the retention of the two streptococcal species using the saliva from the person with or without caries activity.

\section{Influence of toothpaste on the retention of streptococci on toothbrushes}

The chlorhexidine-digluconate-containing toothpaste had no influence on the amount of viable bacteria of either species at time point $T_{0}$ either in the presence or absence of saliva. For $S$. mutans, a reduction in cell numbers over time $\left(T_{24}\right)$ was detectable for all toothbrushes. For $S$. sanguinis, a reduction was only detected for the Colgate $360^{\circ}$ toothbrush after 24 hours. The influence of the antibacterial toothpaste could not be determined for the other three toothbrushes because the bacterial numbers at $\mathrm{T}_{24}$ compared with those in the settings without toothpaste were already below the detection limit. There were no significant differences between any tested variables $(p>0.05)$.

\section{DISCUSSION}

This study demonstrated that the contamination of different toothbrushes with S. sanguinis and $S$. 
mutans occurred. The microbial load decreased after a period of dry storage and the additional use of toothpaste. However, the differences were not significant for our experimental setting.

These observations are in agreement with previous studies examining the presence of different microorganisms on toothbrushes $5,8,9,15,16,20,21$.

The present study was conducted in vitro. This approach allows for the control of several parameters that may influence the retention of bacteria on toothbrushes, such as the bacterial species used to contaminate the toothbrushes. During normal toothbrush use, the indigenous oral microflora will adhere to the toothbrush. There is, however, high inter- and intraindividual variability in the bacterial load and the composition of the oral microflora. Oral hygiene measures and the dental health status of patients are closely related to the presence of commensal and potentially pathogenic microorganisms ${ }^{24}$. A correlation between the dental status of patients and the microbial load of toothbrushes was demonstrated ${ }^{8}$. Therefore, the use of specific bacterial strains, such as S. mutans and $\mathrm{S}$. sanguinis, ensures a reproducible and standardized contamination protocol. A previous study also examined the retention and viability of $S$. mutans on toothbrushes using an in vitro approach ${ }^{26}$. This study revealed decreasing numbers of $S$. mutans with time. Viable bacterial cells were detectable on the toothbrushes for up to four hours ${ }^{26}$.

S. mutans was selected due to its significant role in the etiology of dental caries ${ }^{13}$. Its primary ecological niche is the supragingival plaque. S. sanguinis was included in the present study because of its relevance in supragingival and subgingival biofilm formation ${ }^{11}$. Streptococci belong to the group of early oral plaque colonizers. They enable the subsequent attachment and multiplication of so-called late colonizers, which may include potential pathogenic bacteria ${ }^{11}$. Bacteria classified as late colonizers often require an anaerobic environment and prefer receptors on other oral bacteria ${ }^{11}$. Nevertheless, toothbrushes infected with a wide spectrum of microorganisms also exhibited gram-negative, strict anaerobic bacteria, such as Porphyromonas gingivalis ${ }^{15}$. Specific contamination with Aggregatibacter actinomycetemcomitans was further evaluated in a clinical setting ${ }^{16}$.

While no differences between S. mutans and S. sanguinis retention were detectable after three minutes, $S$. sanguinis levels were decreased to a greater extent after 24 hours, both with and without the use of antimicrobial toothpaste. This result suggests that $S$. mutans is more resistant against both adverse environmental conditions, such as starvation and dehydration, and the antimicrobial effect of the chlorhexidine-digluconate-containing toothpaste. Furthermore, the adhesion of S. mutans may be stronger than that of $S$. sanguinis. This finding possibly reflects the greater pathogenic potential of the cariogenic species S. mutans. This microorganism is characterized by several virulence factors, such as acid production, the synthesis of extracellular polysaccharides and the expression of adhesins on the bacterial surface ${ }^{13}$. These adhesins allow the bacteria to attach to oral surfaces and other species. S. sanguinis is also able to adhere to tooth and bacterial surfaces ${ }^{11}$.

Using an in vitro mono-species approach, the potential synergisms and antagonisms between oral bacteria cannot be taken into account ${ }^{11}$. Phenotypes of bacteria from the oral cavity, especially those derived from dental biofilms, may also differ from these in vitro planktonic bacteria with regard to their adhesion characteristics ${ }^{11}$. Biofilms are complex three-dimensional structures that consist of microbial colonies surrounded by an exopolymer matrix $^{11}$. The diversity of the oral microbiota, which is comprised of over 1,000 different bacterial species $^{28}$, limits the possibility of reflecting the intraoral environment in a multi-species biofilm laboratory model. In addition to microbial aspects, the in vitro design of the present study assures uniform toothbrush practice methods, rinsing and storage conditions, as well as consistent toothbrush wear.

The present study demonstrated the influence of storage time, toothbrush type, human saliva and toothpaste use on toothbrush contamination.

Bacterial counts decreased over time. A reduction in counts was detectable after a storage period of 24 hours, although S. mutans still remained detectable. This finding implies that the non-humid atmosphere and the absence of nutrients during dry storage prevent the survival of most microorganisms. The observed decrease in the number of microorganisms with storage time is in accordance with previous observations. Most studies included an examination time of up to 24 hours ${ }^{5,8,26}$. While some authors reported a critical reduction in the proportion of vital microorganisms within twelve hours, others described a gradual decrease over a period of 48 hours $^{21,23}$.

The present investigation revealed some differences in bacterial counts using different types of toothbrushes. The Colgate $360^{\circ}$ toothbrush harbored more $S$. sanguinis than the other toothbrushes after 24 hours. This finding indicates that different toothbrush designs may influence the retention of microorganisms. Different toothbrush components, such as the bristle number or length and the bristle material, may affect colonization. As a result of their surface morphology, in terms of roughness and microscopic defects, toothbrush bristles may further provide niches for bacteria. The 
additional soft rubber polishing cups and textured tongue and cheek scraper on the back of one toothbrush head may provide an additional surface for bacterial adhesion.

A previous publication compared different toothbrushes with respect to bacterial retention ${ }^{5}$. The authors concluded that bacteria retention increased with the exposed area of the toothbrush. Whether bristles with anchoring part harbor more bacteria compared to bristles without anchoring part was analyzed ${ }^{21}$. It was demonstrated that the results for bristles with and without anchoring parts did not differ ${ }^{21}$.

However, the impact of different types of anchoring parts on bacterial retention was subsequently revealed ${ }^{30}$. In addition, the degree of toothbrush bristle wear seems to have an impact on $S$. mutans retention, with new toothbrushes harboring more bacterial cells ${ }^{9}$. In addition, hard deposits between the toothbrush bristles were shown to be niches for bacterial growth ${ }^{10}$.

Several studies examined the value of coated tufts, including triclosan and chlorhexidine ${ }^{17}$. Inconsistent results were obtained regarding a potential superior effect of these impregnated bristles compared with non-coated bristles.

The use of toothpaste seems to affect the survival rate of bacteria, but it appears to be insufficient to prevent bacterial contamination. In our study, there was a greater reduction in microbial load after 24 hours of dry storage for both species and all toothbrushes. Additive bactericidal effects of toothpastes have also been observed in clinical and in vitro studies $4,18,20,29$. It was noted that toothpastes differ in their antibacterial activity depending on their composition ${ }^{20}$.

Dentifrices usually contain several therapeutic substances with antimicrobial activity $20,21,29$. The toothpaste used in the present investigation contained $0.12 \%$ chlorhexidine digluconate as a therapeutic agent. Chlorhexidine is considered to be the gold standard of oral hygiene ${ }^{22}$. Its bactericidal effect is based on its adsorption to bacterial cell surfaces, resulting in increased cell membrane permeability or the precipitation of cytoplasm. Chlorhexidine that is adherent to tooth surfaces exhibits prolonged bacteriostatic action ${ }^{1}$. This characteristic could therefore explain the observed influence of chlorhexidine on bacterial viability.

A greater amount of bacteria adhered to the toothbrushes when they were suspended in saliva from a person with either high or low caries activity. Differences in saliva composition due to different caries activity may therefore not influence the adhesion process of $S$. mutans and S. sanguinis in this in vitro approach. On tooth surfaces, salivary molecules, such as proteins, glycoproteins and mucines, first adsorb and form an acquired pellicle, which provides binding sites for bacterial receptors ${ }^{11}$. Salivary constituents most likely also bind to the toothbrush surfaces and thereby facilitate the colonization of bacteria, which may actively bind to the saliva-coated toothbrushes or could be passively retained due to the high viscosity and capillary action of saliva ${ }^{16}$. Regarding the known hydrophobic and electrostatic interactions between microorganisms and solid surfaces, however, microbial attachment seems to be more conceivable ${ }^{11}$.

Toothbrush contamination seems to be clinically relevant because subsequent intraoral translocations of microorganisms or reinfections may occur ${ }^{19}$. Several studies revealed the translocation of cariogenic and periodontopathogenic species from a contaminated oral hygiene aid or a dental instrument. The translocation of $S$. mutans strains was demonstrated via dental floss. Bacteria were further transferred by means of dental explorers ${ }^{14}$.

\section{CONCLUSION}

In conclusion, the present study showed that in vitro bacterial adhesion and survival of $S$. sanguinis and $S$. mutans on toothbrushes is possible with no remarkable differences among the toothbrushes. Within the limitations of this study, the use of human saliva of a caries-active and a caries-inactive proband or an antimicrobial toothpaste, containing chlorhexidine, did not lead to significant differences in the microbial load on the toothbrushes tested.

\section{CONFLICT OF INTEREST}

The authors declare that there is no conflict of interest.

\section{ACKNOWLEDGEMENTS}

Parts of this research were conducted by $M$. Bux in partial fulfilment of the requirements for an MD degree from the University of Basel, Switzerland. The authors thank Colgate-Palmolive AG (Thalwil, Switzerland), Curaden AG (Kriens, Switzerland), GABA AG (Therwil, Switzerland) and Trisa AG (Triengen, Switzerland) for provision of the toothbrushes used in this study and the Curaden AG (Kriens, Switzerland) for providing the toothpaste. 


\section{REFERENCES}

1- Addy M. Chlorhexidine compared with other locally delivered antimicrobials. A short review. J Clin Periodontol. 1986;13:957-64. 2-Al-Ahmad A, Wiedmann-Al-Ahmad M, Deimling D, Jaser C, Pelz $K$, Wittmer $A$, et al. An antimicrobial effect from silver-coated toothbrush heads. Am J Dent. 2010;23:251-4.

3- Axelsson P, Nyström B, Lindhe J. The long-term effect of a plaque control program on tooth mortality, caries and periodontal disease in adults. Results after 30 years of maintenance. J Clin Periodontol. 2004;31:749-57.

4- Bertolini PF, Biondi Filho O, Pomilio A, Pinheiro SL, Carvalho MS. Antimicrobial capacity of Aloe vera and propolis dentifrice against Streptococcus mutans strains in toothbrushes: an in vitro study. J Appl Oral Sci. 2012;20:32-7.

5- Bunetel L, Tricot-Doleux S, Agnani G, Bonnaure-Mallet M. In vitro evaluation of the retention of three species of pathogenic microorganisms by three different types of toothbrush. Oral Microbiol Immunol. 2000;15:313-6.

6- De Soete M, Dekeyser C, Pauwels M, Teughels W, van Steenberghe D, Quirynen M. Increase in cariogenic bacteria after initial periodontal therapy. J Dent Res. 2005;84:48-53.

7- Edman DC, Keene HJ, Shklair IL, Hoerman KC. Dental floss for implantation and sampling of Streptococcus mutans from approximal surfaces of human teeth. Arch Oral Biol. 1975;20:1458.

8- Glass RT, Lare MM. Toothbrush contamination: a potential health risk? Quintessence Int 1986;17:39-42.

9- Goldsmith RN, Shey Z, Houpt MI, Fine D, Schreiner H, Greenberg B. Toothbrush bristle wear and adherence of Streptococcus mutans. Pediatr Dent. 2007;29:243-7.

10- Karibasappa GN, Nagesh L, Sujatha BK. Assessment of microbial contamination of toothbrush head: an in vitro study. Indian J Dent Res. 2011;22:2-5.

11- Kolenbrander PE, Palmer RJ Jr, Periasamy S, Jakubovics NS. Oral multispecies biofilm development and the key role of cell-cell distance. Nat Rev Microbiol. 2010;8:471-80.

12- Loesche WJ. Chemotherapy of dental plaque infections. Oral Sci Rev. 1976;9:65-107.

13- Loesche WJ. Role of Streptococcus mutans in human dental decay. Microbiol Rev. 1986;50:353-80.

14- Loesche WJ, Svanberg ML, Pape HR. Intraoral transmission of Streptococcus mutans by a dental explorer. J Dent Res. 1979;58:1765-70.

15- Malmberg E, Birkhed D, Norvenius G, Norén JG, Dahlén G. Microorganisms on toothbrushes at day-care centers. Acta Odontol Scand. 1994;52:93-8.

16- Müller HP, Lange DE, Müller RF. Actinobacillus actinomycetemcomitans contamination of toothbrushes from patients harbouring the organism. J Clin Periodontol. 1989; 16:388-90.
17- Nascimento C, Scarabel TT, Miani PK, Watanabe E, Pedrazzi V. In vitro evaluation of the microbial contamination on new toothbrushes: a preliminary study. Microsc Res Tech. 2012;75:425 .

18- Nelson-Filho P, Isper AR, Assed S, Faria G, Ito IY. Effect of triclosan dentifrice on toothbrush contamination. Pediatr Dent. 2004;26:11-6.

19- Quirynen M, De Soete M, Dierickx K, van Steenberghe D. The intra-oral translocation of periodontopathogens jeopardises the outcome of periodontal therapy. A review of the literature. J Clin Periodontol. 2001;28:499-507.

20- Quirynen M, De Soete M, Pauwels M, Gizani S, Van Meerbeek B, van Steenberghe D. Can toothpaste or a toothbrush with antibacterial tufts prevent toothbrush contamination? J Periodontol. 2003;74:312-22.

21- Quirynen M, de Soete M, Pauwels M, Goossens K, Teughels W, van Eldere J, et al. Bacterial survival rate on tooth- and interdental brushes in relation to the use of toothpaste. J Clin Periodontol. 2001;28:1106-14

22- Rohrer N, Widmer AF, Waltimo T, Kulik EM, Weiger R, Filipuzzi-Jenny $\mathrm{E}$, et al. Antimicrobial efficacy of 3 oral antiseptics containing octenidine, polyhexamethylene biguanide, or Citroxx: can chlorhexidine be replaced? Infect Control Hosp Epidemiol. 2010;31:733-9.

23- Saravia ME, Nelson-Filho P, Silva RA, Faria G, Rossi MA, Ito IY. Viability of Streptococcus mutans toothbrush bristles. J Dent Child (Chic). 2008;75:29-32.

24- Sbordone L, Ramaglia L, Gulletta E, Iacono V. Recolonization of the subgingival microflora after scaling and root planing in human periodontitis. J Periodontol. 1990;61:579-84.

25- Schmidt JC, Zaugg C, Weiger R, Walter C. Brushing without brushing? - a review of the efficacy of powered toothbrushes in noncontact biofilm removal. Clin Oral Investig. 2013;17:687-709. 26- Spolidorio DM, Goto E, Negrini TC, Spolidorio LC. Viability of Streptococcus mutans on transparent and opaque toothbrushes. J Dent Hyg. 2003;77:114-7.

27- Theilade E. The non-specific theory in microbial etiology of inflammatory periodontal diseases. J Clin Periodontol. 1986;13:905-11.

28- Wade WG. The oral microbiome in health and disease. Pharmacol Res. 2013;69:137-43.

29- Warren DP, Goldschmidt MC, Thompson MB, Adler-Storthz $\mathrm{K}$, Keene $\mathrm{HJ}$. The effects of toothpastes on the residual microbial contamination of toothbrushes. J Am Dent Assoc. 2001;132:12415.

30- Wetzel WE, Schaumburg C, Ansari F, Kroeger T, Sziegoleit A. Microbial contamination of toothbrushes with different principles of filament anchoring. J Am Dent Assoc. 2005;136:758-65; quiz 806. 